\title{
Examining the Role of Trust and Risk in the Software-as-a-Service Adoption Decision
}

\author{
Michał Kuciapski \\ University of Gdansk \\ $\underline{\text { m.kuciapski@ug.edu.pl }}$
}

\author{
Paweł Lustofin \\ Cracow University of Economics \\ plustofin@gmail.com
}

\author{
Piotr Soja \\ Cracow University of Economics \\ eisoja@cyf-kr.edu.pl
}

\begin{abstract}
The current study investigates the role of risk and trust in the Software-as-a-Service (SaaS) adoption decision. Drawing from the Web-Trust Model and Institutional Isomorphism Theory, the study proposes a multi-layered model explaining antecedents of the propensity to adopt SaaS. The model is next verified drawing from the opinions of 154 Polish IT practitioners with the Partial Least Squares (PLS) research approach. The results obtained in PLS analysis illustrate that both risk and trust directly influence the decision to adopt SaaS. However, the role of trust turned out more pronounced as trust also influences the decision to adopt SaaS indirectly through risk and, unlike risk, is also influenced by professional influence and external pressure. The findings also reveal varied importance of different types of risk for the SaaS adoption decision, highlight the paramount importance of operational risk and low significance of economic and legal risk.
\end{abstract}

\section{Introduction}

The emergence of new digital technologies referred to as SMACIT (Social, Mobile, Analytics, Cloud and Internet of Things (IoT)) gave rise to both some great opportunities and grave risks for firms from virtually all industries [1]. Digital transformation, which is concerned with the innovative applications of these technologies, entails far-reaching changes in company's business model, products, processes, and organizational structure [2]. Furthermore, digital transformation may involve entirely new or disruptive business models. By pursuing digital transformation initiatives companies strive to enhance customer experience and streamline their operations. Failure to identify and exploit unique value proposition of these new digital technologies poses grave strategic risk to even well-established firms with relatively strong market positions [3].

The use of cloud computing (CC) technologies has been emphasized to be instrumental for the swift execution of digital transformation strategy which requires from companies both speed and agility [3]. Digital strategies focus on delivering unique, integrated business capabilities in ways that are responsive to changing business conditions [4]. Thus, by offering requisite scalability [5], easy maintenance, rapid deployment [6], and cost-efficiency [7; 8] cloud computing facilitates the execution of digitalization strategy.

The successful introduction of digital services such as integrated IoT or seamless omnichannel customer experience requires a strong operational backbone which ensures flawless execution of transactions and reliable access to critical operational data [1]. In this regard, the Software-as-a-Service (SaaS) model for delivering enterprise applications with its short implementation cycles and flexibility reflected both in the model's scalable nature and convenient functional scope management appears particularly beneficial. For example, a Spanish firm Ferrovial managed to build its operational backbone in just 6 months by adopting HR and purchasing systems in the SaaS model [1].

SaaS refers to applications running on a cloud infrastructure and delivered as services over the Internet in a convenient, on-demand fashion [9;]. This IT model is also characterized by low entry-costs [10] thereby enabling clients to overcome potential budgetary constraints. On the downside, however, the cloud computing model has also been associated with some significant risks and challenges, such as security-related [7; 11] and performance risks [7] which inhibit its adoption. Thus, while faster time-to-market, automatic scalability, and convenience of subscription-based payment models facilitate the development of the socalled operational backbones, perceived risks may stall SaaS adoption decision.

Consequently, as extant studies suggest, the role of trust in the adoption of SaaS and cloud computing is increasing $[5 ; 12]$. Nonetheless, these studies focus solely on trust in security and overlook the importance of vendor characteristics, such as their expertise and competency level, which are essential in building trust 
with clients and help them to overcome perceptions of uncertainty and risk associated with pursuing SaaS. In this respect, the definition and operationalization of trust should capture its multi-dimensional nature and aspects which are of particular importance in the context of SaaS adoption decision. Another important aspect of trust concerns institutional influences which may play an important role in shaping client's awareness of new technologies, particularly in the early stages of innovation adoption [13]. Overall, due to the limitations of prior studies concerning the role of trust in the SaaS adoption decision and the importance of potential benefits that this model offers, particularly in the context of digital transformation initiatives, our study appears both important and timely.

The key goal of our research is to investigate the role that trust plays in the decision to adopt the SaaS model. In doing so, we strive to find an answer to the following research question: What is the role of trust in mitigating perceptions of SaaS-related risk and increasing the propensity to adopt the SaaS model?

The paper is organized as follows. In the next section we introduce the theoretical background associated with various facets of SaaS-related risk and the role of trust in the decision to adopt this IT sourcing model. Further, we describe our research method, which is followed by the presentation of results. Then we discuss our findings, explain implications, and close the study with concluding remarks.

\section{Research Background}

\subsection{SaaS-related risk}

The SaaS model, with the global market valued at 99 billion USD in 2019 [14], continues to gain popularity. Nevertheless, its potential to become a reliable and universal IT model for delivering all types of application services such as ERP systems, production and engineering applications, has been questioned [7]. In particular, because of the multi-tenant nature of SaaS applications, their adjustments to idiosyncratic business processes are significantly more limited than in the case of on-premise implementations [15]. Consequently, despite potential cost savings, clients may be unable to reap the expected benefits from the adoption of such systems.

The idea of an on-demand provisioning of application services from the third-party owned data centers, which is central to the SaaS model, dates back to the late 1990s, the height of the dot.com boom [e.g., 16]. The Application Service Provisioning (ASP) model was depicted as the modern form of pay-as-you-go business computing, touted to reduce Total Cost of Ownership (TCO) of IT, provide $24 / 7$ availability of applications, increase agility and flexibility of organizations, and enable access to cutting-edge software and/or skills [16]. Nevertheless, due to the lack of cultural, social, organizational and technical readiness [16], the ASP model failed to live up to its expectations, which eventually led to its demise. Because of the shortcomings of the SaaS model associated with low customizability of SaaS applications and the failure of its predecessor (the ASP model), clients may perceive the adoption of SaaS applications to be risky. Therefore, we hypothesize that the perceived risk of the SaaS model impacts on the decision to adopt this IT sourcing model.

\subsection{The role of trust in the adoption of SaaS}

The role of trust was confirmed to be essential for establishing long-standing relationships in the IT outsourcing context [e.g., 17] and was shown to constitute a key success factor in any type of ecommerce initiative [18]. Extant research suggests that trust in the ability, integrity, and benevolence of cloud vendors remains an important factor influencing the propensity to adopt the cloud computing model [12]. Trust in the SaaS delivery model relates to perceived quality of services offered by vendors [55], resulting from their reputation, experience, and competences, as well as financial stability and global scope of operations.

The role of trust in the SaaS adoption decision is exacerbated by the significant number and complexity of potential risks related to the SaaS model. Further, the McKnight's Web-Trust Model emphasizes the importance of vendors' experience with and competencies related to SaaS technologies in building trust-based relationships with clients [18]. Also, in line with the key conclusions stemming from the studies on ASP and CC adoption, we recognize that SaaS vendor's reputation, global reach of operations [6] and financial stability [e.g., 16] may shape the perceived trustworthiness of a vendor.

As recent history shows, SaaS providers are prone to financial troubles. Some famous SaaS bankruptcies include 2e2 [19] and Cloudmine [20]. Thus, Marston et al. [21] emphasize the importance of financial transparency, as the risk of cloud provider bankruptcy remains a significant concern among many users. Clients are also concerned with security [e.g., 7; 11], legal [22], economic [7], privacy and performance issues as well as the vendor's capacity to deliver benefits related to SaaS applications [e.g., 7; 11]. Consequently, major cloud providers such as Amazon Web Services, Microsoft Azure and Google Cloud Platform put much effort into demonstrating their security credentials by acquiring existing security standards (e.g., SOC1, SOC2, ISO/IEC 2700) [23]. Salesforce, a producer of a 
leading SaaS CRM solution, on the other hand, shares the data concerning the availability of its systems with clients in real-time [24]. Therefore, we hypothesize that perceived trust in IT providers influences both the propensity to adopt the SaaS model and perceived risk surrounding the adoption of this IT sourcing model.

\subsection{Security risks}

Security risks $[7 ; 11 ; 22]$ and data security risks [25] exert a strong and negative impact on the propensity to adopt CC and SaaS. In the SaaS model, clients have no control over the datacenter, security controls or employment procedures. Thus, the SaaS model is also burdened by non-technology related vulnerabilities which stem from a lack of employee screening and poor hiring practices, lack of customer background checks, and lack of security education [25].

SaaS benefits are derived directly from the lower layers of cloud computing, such as PaaS and IaaS. Nevertheless, the security of higher layers is dependent on the security of lower layers [26; 27]. Furthermore, dependencies on and between deeper layers of cloud computing will be even more profound when they are provisioned by more than one provider [26; 27; 28]. It is not uncommon that the SaaS provider relies on platform services from another cloud provider, who in turn uses infrastructure services provisioned by yet another one. Since cloud applications are delivered through the Internet, they are also exposed to various external security risks, such as denial-of-service (DoS) or distributed denial-of-service (DDoS) attacks [29]. Therefore, we hypothesize that perceived IT security risk related to the use of the SaaS model has an impact on the perceived level of risk associated with the Software-as-a-Service model.

\subsection{Operational risks}

Prior literature suggests that the perceived operational and, in particular, performance risk, have a moderate and significant impact on the adoption of SaaS [7; 11]. Operational risk is mainly related to the possibility that SaaS may not deliver the expected level of service in terms of system availability, its resistance to erroneous functioning, and employed security measures related to disaster recovery and backups, taking into account the perspective of services quality offered by the vendors. Furthermore, SaaS applications are delivered from third-party-owned data centers over the public Internet. Consequently, undisrupted delivery of application service is dependent on many parties such as Internet and SaaS providers over which clients have limited control. Also, the risk of service debasement, i.e. any reduction in the quality of service received by the client $[30 ; 31]$ and application unavailability may have a negative impact on productivity and/or lost revenues. Therefore, we hypothesize that perceived operational risk related to the use of the SaaS model has an impact on the perceived level of SaaS-related risk.

\subsection{Economic risks}

Economic risks were shown to be a strong inhibitor of the SaaS adoption [7]. First, SaaS vendors may act opportunistically and impose higher charges for their services after some initial period. This risk is exacerbated by the fact that most IT contracts are deficient in charge variation clauses [32]. Second, in the SaaS model, it may be harder to control the demand for subscription-based services and compliance with the licensing terms and conditions, both of which may impact directly the subscription charges. In this respect, White and Barber [33] posit that SaaS subscriptions are not a turnkey fix to licensing complexity, but will increase cost risks and add to the demands on SAM (Software asset management). They debunk the myth that it is impossible to be out of compliance with SaaS as there are clear terms and conditions associated with the use of SaaS solutions. For example, as Snow Software, a global leader in SAM applications, emphasizes, with SaaS it may be easier to spin up certain IT components without having to pay for them immediately [34]. Furthermore, Sautelle and Biehl [34] emphasize the economic risk stemming from user violations related to using client-side software components such as plug-ins and applets, or surpassing of geography-related constraints.

Third, existing studies [e.g., 35] suggest that clients possess rather obscure financial data concerning costs of internally provisioned IT services. Specifically, the Zarnekow and Brenner's [35] study indicates that cost data is often incomplete and based on estimates. High accuracy of costs related to application life-cycle possessed by IT clients is usually limited to planning and initial development stages [35]. Consequently, clients may find it difficult to assess SaaS-enabled cost savings. In sum, then, we hypothesize that perceived economic risk related to the use of the SaaS model has an impact on the perceived level of SaaS-related risk.

\subsection{Migration-related risks}

In the SaaS model clients entrust third-parties with some of their most valuable assets - mission-critical data and rely on them to provide application services supporting both daily operations and strategic planning. Companies, however, must always rely on these services, also during a change of applications or IT providers. In this respect, lack of general legal 
requirement for a vendor to provide clients with data export facilities in the EU is a good case in point. In consequence, the assistance of SaaS vendor in migration to another vendor or on-premises infrastructure depends entirely on the client's contractual agreement with the vendor [36]. Thus, if the client decides to terminate the SaaS contract, it may face the switching costs related to data and/or service migration either to other SaaS providers or to an on-premises solution. Further, unless there are no switching costs, clients have limited bargaining power over IT vendors to provide the agreedupon level of service [37].

Findings of the study conducted by Dutta et al. [38], which explores various types of cloud-related risks, suggest that IT clients are concerned about the difficulty to change cloud vendors even in the case of service dissatisfaction. Thus, we hypothesize that perceived migration risk related to the use of the SaaS model has an impact on the perceived level of SaaS-related risk.

\subsection{Legal risks}

The SaaS delivery model comes with an increased reliance on third-party providers as compared to other IT delivery models. This reliance may become accentuated by inadequate contractual assurances, lack of controls and guarantees, risk of non-conformance with compliance requirements, and insufficient Service Level Agreement (SLA) [28; 32; 39]. In particular, most IT contracts fail to meet the requirements of what is considered a yardstick for the fair and equitable contract thereby exacerbating potential legal ramifications in the case of conflict with vendor [32]. Poor contractual agreements that fail to reflect all details in the SLA which are associated with cloud computing are among three major legal risks in the study by Dutta et al. [38].

Firms in many industries are bound by various regulations (e.g., HIPPA, PCI DSS, SOX, GDPR) which impose on them strict requirements related to Information System controls, the privacy of personal information as well as proper security standards. Failure to comply with these regulations may lead to a compromised reputation, financial losses and even the suspension of business operations. Further, pursuing the SaaS delivery model may expose clients to issues and risks surrounding data residency. In particular, legal rights based on which a public institution or the government is granted access to the firm's data may vary significantly between countries. Also, as demonstrated by Dutta et al. [38], inconsistent data protection laws adopted by different countries where cloud data are generated and stored constitute the second most severe issue surrounding cloud computing adoption. Therefore, we hypothesize that perceived legal risk related to use of the SaaS model influences the perceived level of SaaS-related risk.

\subsection{Institutional pressures}

Extant literature on IT adoption [40; 41] emphasizes the role of institutional pressures comprising external coercive and mimetic pressures and norm-setting influences such as these exerted by professional IT community. Further, a study by Saya et al. [42] illustrates that institutional influences (e.g., government regulations, pressures exerted by customers, suppliers, competitors, strategic partners and professional bodies) have strong and significant impact on perceived accessibility, scalability, cost effectiveness and security profile of cloud computing. Institutional Theory posits that decisions made by organizations may be determined by three mechanisms: 1) organization may be under pressure from organizations they are dependent on, 2) they mimic decisions made by their competitors, usually sector leaders, and finally 3) their viewpoint may be shaped by the impact of professionals and existing norms [43]. External pressure accounts for both coercive pressures and mimicking behaviors. Professional influence accounts for the impact stemming from the growing professionalization of the IT sector. Therefore, we hypothesize that both external pressures and professional influence will influence the perceived SaaS-related risk and the level of trust in SaaS vendors.

\section{Research Method}

As presented in the previous section, there exist many considerations related to trust and risk during the decision to adopt the SaaS delivery model. Accordingly, the variables trust $(\mathrm{T})$ and risk $(\mathrm{R})$ constitute the basis of the proposed model exploring the role of trust and risk when making a decision to adopt the SaaS delivery model in an organization (Figure 1).

The conducted literature review, summarized in the previous section, points out that risk should be treated as a complex construct. As a result, drawing from the risk-benefit models adopted in prior studies [7; 11], in our model the general SaaS-related risk is treated as a mediator for a number of indirect determinants (Figure $1)$, representing particular types of risk, such as: security risk (SR), migration risk (MR), economic risk (ER), operational risk (OR) and legal risk (LR).

IT adoption literature points out that perceived trust and risks associated with the use of technology might depend on opinion leaders, competitors, vendors, and other stakeholders. Isomorphic changes are driven by 


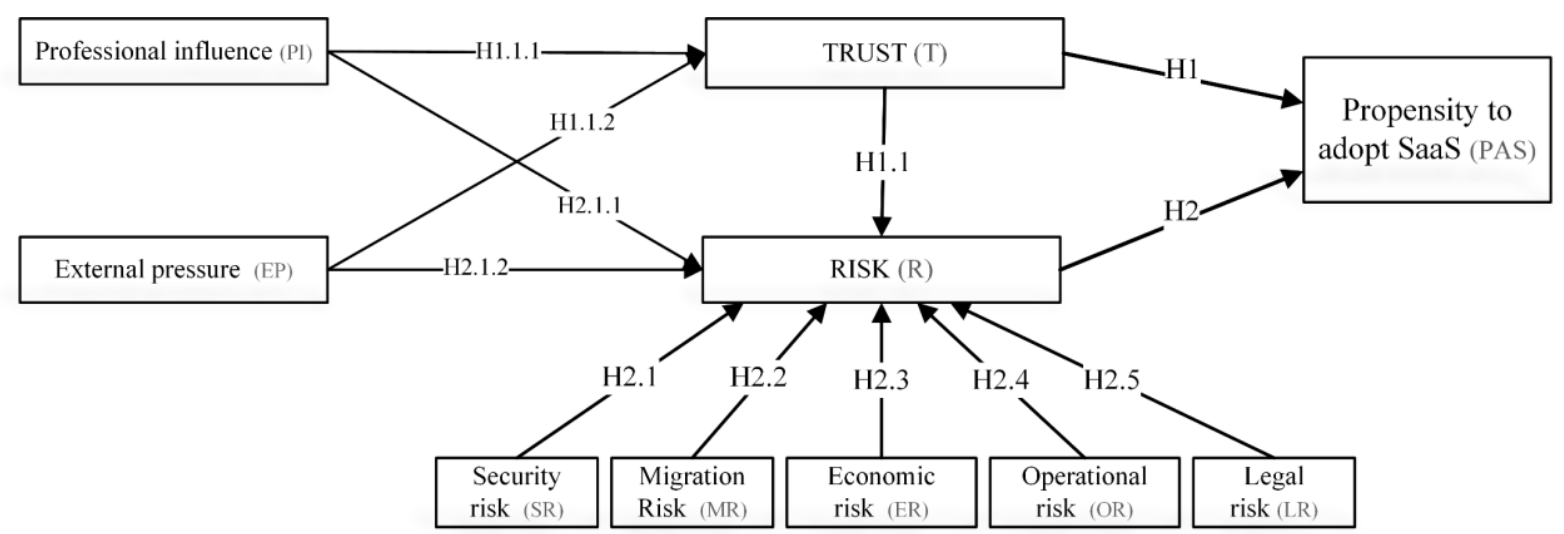

Figure 1: Research Model

coercive, mimetic and normative pressures [7; 11], which are related to professional influence and external impact related to mimetic and coercive influences. Therefore, the model includes connections between professional influence (PI) and external pressure (EP) being external variables, and $\mathrm{T}$ and $\mathrm{R}$ highlighted as direct determinants of propensity to adopt SaaS (PAS).

As discussed earlier, prior studies support belief that trust in third-parties is an important factor associated with their perceived expertise, integrity, financial stability and, as a result, possibility of longstanding relationships $[12 ; 17 ; 21]$. Based on these premises, a relationship between trust and risk is enclosed in the proposed model (Figure 1).

The existence of dependency relations between variables in the model (Figure 1) was verified through 12 hypotheses introduced in the previous section and summarized in Table 1. Quantitative research was applied with data collection based on the survey as the research instrument. Gathering of responses was conducted by the means of computer-assisted web interview (CAWI). The survey consisted of two sections. The first one introduced a set of respondent classification questions. The second part of the survey consisted of 38 statement assertions formulated in accordance with referenced studies considering the SaaS perspective -3 to 5 statements for each connection. Each question was measured using a 7-point Likert scale. More details about the research instrument can be found at https://tinyurl.com/saasdata.

Because of the lack of a reliable sampling frame, it is difficult to conduct a random sampling for all potential SaaS technology users. Therefore, similar to Wang et al. [57], this study adopted a non-random sampling technique (i.e. convenience sampling) to start collecting the sample data. Subsequently, to have a proper sampling frame and a representative sample for the entire population, organizations of various sizes and years of activity, from various regions and sectors were chosen. The research data was collected via CAWI and during face-to-face meetings.

The proposed multidimensional model was verified by the means of the Partial-Least-Squares Structural Equations Modelling (PLS-SEM) approach, a secondgeneration technique [44] also referred to as the path analysis with latent variables [45]. PLS-SEM is well suited not only for predictive models but also for the confirmation of research models, especially in their early development stages [46]. It is also appropriate for suggesting cause-effect relationships [47; 48]. A twostep process integral to PLS-SEM was conducted [49], encompassing the assessment of the outer model followed by the evaluation of the inner model:

- outer model - evaluation of indicator reliability (loadings), internal consistency reliability (Composite reliability, CR) as well as convergent (Average variance extracted, AVE) and discriminant (Heterotrait - monotrait ratio, HTMT) validity [49];

- inner (structural) model - including criteria such as: the coefficient of determination (R2), the blindfolding-based cross-validated redundancy measure (Q2), and the statistical significance and relevance of the path coefficients $[50 ; 51]$.

\section{Research Results}

During the period of 7 months, starting January 2019, 154 surveys have been received. As all respondents indicated sufficient knowledge and experience with SaaS applications, no observations were deleted from the sample. In PLS-SEM the minimum sample should meet one of the following two conditions [44]: (1) ten times the largest number of formative indicators used to measure one construct; or (2) ten times the largest number of structural paths directed at a particular latent construct in the structural model. It follows than that our sample meets the requirements concerning the minimum sample size. 
Table 1: Research Hypotheses

\begin{tabular}{|c|c|c|}
\hline Hypoth. no. & Connection & Hypothesis \\
\hline H1 & $\mathrm{T}->$ PAS & $\begin{array}{l}\text { The perceived trust in the Software-as-a-Service delivery model influences the } \\
\text { decision to adopt SaaS. }\end{array}$ \\
\hline $\mathrm{H} 2$ & R -> PAS & $\begin{array}{l}\text { The perceived risk of using the Software-as-a-Service delivery model influences } \\
\text { the decision to adopt SaaS. }\end{array}$ \\
\hline H1.1 & T-> R & $\begin{array}{l}\text { The perceived trust in the Software-as-a-Service delivery model influences the } \\
\text { perceived risk of using SaaS. }\end{array}$ \\
\hline $\mathrm{H} 2.1$ & SR-> R & $\begin{array}{l}\text { The perceived security risk of using the Software-as-a-Service delivery model } \\
\text { influences the perceived general risk of using SaaS. }\end{array}$ \\
\hline $\mathrm{H} 2.2$ & MR -> R & $\begin{array}{l}\text { The perceived migration risk of using the Software-as-a-Service delivery model } \\
\text { influences the perceived general risk of using SaaS. }\end{array}$ \\
\hline $\mathrm{H} 2.3$ & ER-> R & $\begin{array}{l}\text { The perceived economic risk of using the Software-as-a-Service delivery model } \\
\text { influences the perceived general risk of using SaaS. }\end{array}$ \\
\hline $\mathrm{H} 2.4$ & OR-> R & $\begin{array}{l}\text { The perceived operational risk of using the Software-as-a-Service delivery model } \\
\text { influences the perceived general risk of using SaaS. }\end{array}$ \\
\hline $\mathrm{H} 2.5$ & LR-> R & $\begin{array}{l}\text { The perceived legal risk of using the Software-as-a-Service delivery model } \\
\text { influences the perceived general risk of using SaaS. }\end{array}$ \\
\hline H1.1.1 & PI-> T & $\begin{array}{l}\text { Opinions of professionals impact on the perceived trust in the Software-as-a- } \\
\text { Service delivery model. }\end{array}$ \\
\hline H1.1.2 & PI-> R & $\begin{array}{l}\text { Opinions of professionals impact on the perceived risk of using the Software-as-a- } \\
\text { Service delivery model. }\end{array}$ \\
\hline $\mathrm{H} 2.1 .1$ & $E P \rightarrow T$ & $\begin{array}{l}\text { The perceived external pressure impacts on the perceived trust in the Software-as- } \\
\text { a-Service delivery model. }\end{array}$ \\
\hline $\mathrm{H} 2.1 .2$ & EP -> R & $\begin{array}{l}\text { The perceived external pressure impacts on the perceived risk of using the } \\
\text { Software-as-a-Service delivery model. }\end{array}$ \\
\hline
\end{tabular}

Survey participants classification data pointed out that respondents represented various: job experience (from a couple of months up to 40 years), services delivery methods used (on-premise, SaaS and hybrid), current use of SaaS (yes and no), type of job position (specialists, management and top management), departments (18 have been distinguished), sectors (25 have been indicated in accordance with Statistical Classification of Economic Activities in the European Community, NACE), capital source (domestic and foreign), company size (from below 9 employees to over
1000) and SaaS use experience (from beginners to seasoned practitioners). Obtaining responses from employees representing a wide spectrum of characteristics enabled us to generalize the survey results.

The outer model validation results proved the proposed model to be valid as indicators satisfied the required threshold values: loadings ( $>0.708)$, composite reliability ( $>0.70$ and $<0.90$ ), average variance extracted $(>0.5)$ and heterotrait-monotrait ratio $(<0.9)$. The positive result of the outer model validation enabled us

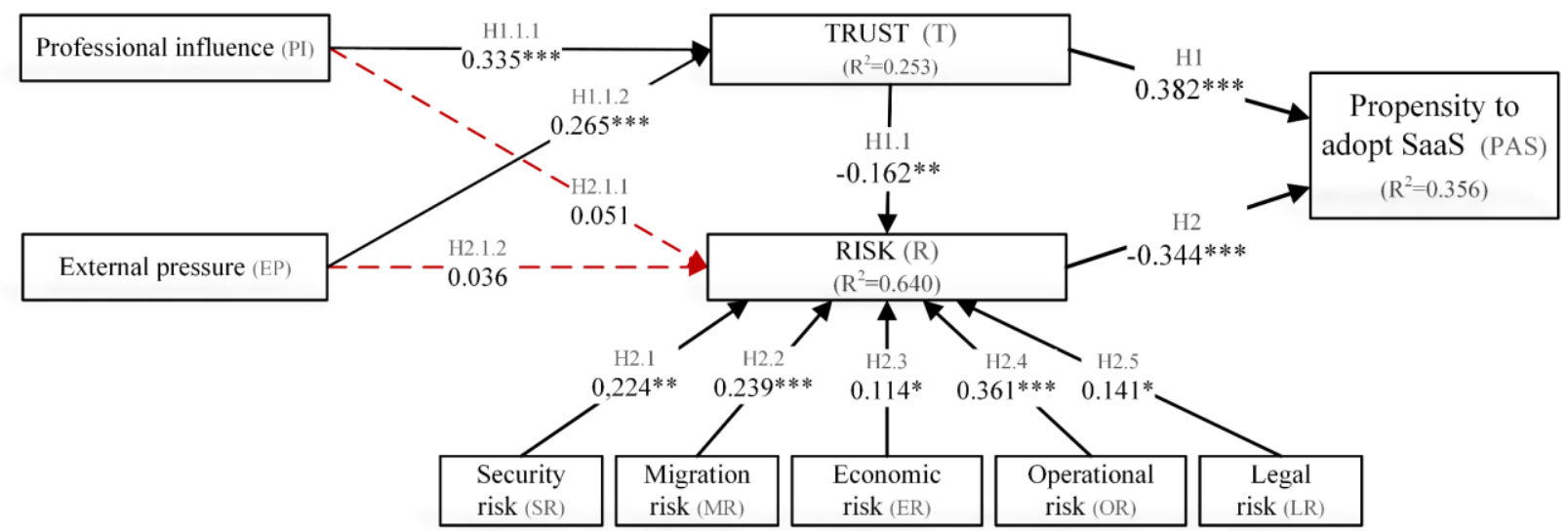

Figure 2: Research Model Validation 
to conduct the regression analysis and thus to verify the 12 stated hypotheses given in Table 1 and illustrated in Figure 1. More details about the PLS results can be found at: https://tinyurl.com/saasdata.

Figure 2 presents the inner model validation results. In accordance with statistics rules for inner model validation, paths were evaluated by calculating $\mathrm{p}$-values and t-statistics. The standardized $\beta$-coefficients were calculated to measure the strength of the connections and the coefficient of determination $\left(\mathrm{R}^{2}\right)$ was determined to explain the power of relationship.

As the proposed model, defined in Figure 1, is multidimensional, the total effects of variables on PAS were calculated as the sums of the variables' direct and indirect impact on PAS. Calculating such indicators allows us to better explain the extent to which the determinants influence the propensity to adopt SaaS in the trust-risk context (Table 2).

Table 2: Total Effects of Particular Variables on Propensity to Adopt Software-as-a-Service

\begin{tabular}{|l|c|c|c|}
\hline Variable & Direct & Indirect & Total \\
\hline T & 0.382 & 0.056 & 0.438 \\
\hline R & -0.344 & & -0.344 \\
\hline PI & & 0.129 & 0.129 \\
\hline OR & & -0.124 & -0.124 \\
\hline EP & & 0.1 & 0.1 \\
\hline MR & & -0.082 & -0.082 \\
\hline SR & & -0.077 & -0.077 \\
\hline LR & & -0.049 & -0.049 \\
\hline ER & & -0.039 & -0.039 \\
\hline
\end{tabular}

According to Table 2, all variables except risk (R) have an indirect effect on the decision to adopt SaaS. However, MR, SR, LR and ER indirect impact on PAS must be acknowledged as not significant due to beta value being lower than 0.1 .

\section{Discussion}

The study results, presented in Figure 2 and Table 2 , enable us to formulate several conclusions both from theoretical and practical perspectives. Interpreted from the theoretical standpoint, they allow us to explain the Software-as-a-Service adoption decision from the trust and risk perspectives.

First and foremost, both trust (T) and risk (R) turned out to impact the propensity to adopt SaaS (PAS), hence hypothesis $\mathrm{H} 1$ and $\mathrm{H} 2$ were confirmed. Moreover, the significance level and the strength of influence turned out to be highly similar for both variables (Figure 2 ). $\mathrm{T}$ $(\beta=0.382, p<0.001)$ and $R(\beta=-0.344, p<0.001)$ were confirmed to significantly affect PAS with a moderate strength. This highlights that the decision to adopt SaaS in an organization depends on the trust in the SaaS delivery model and perceived risk associated with its use. General trust can be interpreted as referring to trust in SaaS providers and stability of SaaS-based solutions. Risk concerns all perceived threats resulting from SaaS use as compared to on-premise solutions. The current study results, highlighting trust and risk as important determinants of technology adoption, are convergent with findings of prior studies indicating the important role of trust for long-standing relationships in the IT outsourcing context [e.g.17] and emphasizing the SaaS adoption's link with perceived risks $[11 ; 22]$.

On the one hand, not surprisingly, trust has been confirmed to influence the risk as hypothesis $\mathrm{H} 1.1$ has been supported (Figure 2). On the other hand, a relatively low strength of relationship $(\beta=-0.162)$ was not the expected value. This means that promoting trust in SaaS mitigates the perceived risk associated with its use; however, it should not be applied as a main solution.

The direct impact of the variable $\mathrm{T}$ on the variable $\mathrm{R}$ increases T's total impact ( $\beta=0.438$ ) on PAS (Table $2)$ due to an additional indirect influence $(\beta=0.056)$. This allows us to recognize trust as a significantly more important determinant of propensity to adopt SaaS than risk. Such a finding supports the results of the study [12] highlighting that the integrity, benevolence and competencies of vendors are very important factors influencing the propensity to adopt a cloud computing model.

Trust and risk explain propensity to adopt SaaS in 36 percent $\left(\mathrm{R}^{2}=0.356\right)$. In technology adoption research field, such a value of $\mathrm{R}^{2}$ where only one perspective is evaluated, is recognized as a moderate one [56]. In this respect, the study of Lustofin et al. [52] points out that the business-IT alignment perspective is an even more important approach in explaining propensity to adopt SaaS as it explains PAS in 59 percent. Nevertheless, a moderate $\mathrm{R}^{2}$ implies that the trust and risk perspectives should be an integral part of cloud adoption models.

Apart from PAS, our model also identified antecedents of variables $\mathrm{R}$ and $\mathrm{T}$. Risk is explained to a high degree in 64 percent (Figure 2). All ascribed types of risks, such as security risk (SR), migration risk (MR), economic risk (ER), operational risk (OR) and legal risk (LR) have been confimed to influence general risk (R), hence hypoteses from $\mathrm{H} 2.1$ to $\mathrm{H} 2.5$ have been supported. Such a result higlights the importance of studying various types of risk for technology adoption and is convergent with prior studies [7; 11; 53]. Nevertheless, different types of risk turned out to affect the perception of general risk to a varying degree (Figure 2). The most important risk determinant is operational risk $(\beta=-0.361, \mathrm{p}<0.001)$, while legal $(\beta=0.141, p<0.05)$ and economic $(\beta=0.114, p<0.05)$ risks turned out to impact the general risk perceptions to 
a much lesser degree. In contrast to results obtained by Benlian and Hess [7] and Kim et al. [11], our study suggests that operational risk exerts a stronger impact on the overall SaaS-related risk perceptions than security risk. In a similar vein, by showing that economic risks have a weak, yet significant, impact on the SaaS-related risk, our results call into question findings of a study by Kim et al. [11] which suggests economic risk is an insignificant determinant of SaaS adoption decision.

According to Figure 2, professional influence (PI) and external pressure (EP) influence only perceived trust in the SaaS delivery model (H1.1.1 and H1.1.2) as hypotheses regarding impact on risk $(\mathrm{H} 2.1 .1$ and H2.1.2) were rejected. Trust depends moderately $(\beta=0.335, p<0.001)$ on PI and to a lower extent $(\beta=0.265, p<0.001)$ on EP. PI and EP also explain trust to a moderate extent $\left(\mathrm{R}^{2}=0.253\right)$. Opinions of experts in the SaaS field play a significant role in building perceived trust in using SaaS but turn out to be rather irrelevant as far as perceptions of SaaS-related risks are concerned. Similarly, current trends, principles, best practices and solutions promoted by external experts and providers in the sector represented by an organization appear to influence the perceived trust in the SaaS delivery model but not the perception of related risks. In this respect, our findings support prior studies' results confirming that institutional isomorphic pressure has a positive effect on increasing stakeholder trust [e.g., 54]. However, in turn, isomorphic changes' influence on risk appears not to have been explored in extant studies.

The current research results also have implications for practitioners. First, as trust occurred the most important determinant influencing propensity to adopt SaaS (Table 2), organizations should concentrate in assessing potential SaaS offers from the following perspectives:

- trust in the vendor: financial stability, long-term business prospects and long term support;

- $\quad$ trust in the delivery model of IT solution (system or application): stability of the cloud-based delivery method, stability of pricing system, long term availability and maintenance of products.

Second, as professional influence and external pressure occurred to significantly influence trust in SaaS (Figure 2), organizations should build trust in the SaaS delivery model with the help of opinions of external experts and articles in professional press. In particular, vendors should utilize such channels to promote their offer as trustworthy. In this respect, our results suggest that vendors may shape the adopters' perception of trust to a certain extent and might employ external experts to this end.

Third, our results suggest that risk, being also confirmed as an important SaaS adoption antecedent, must be considered by organizations just as much as trust. However, an important implication stemming from the current study's results relates to differentiation in risk types' impact on propensity to adopt SaaS (Figure 2). According to our results, organizations adopting SaaS or vendors offering SaaS-based solutions should concentrate on aspects associated with operational, security and migration risks. The analysis of economic and legal risks should not be omitted; however, it may be conducted to a less complex extent. Such an implication might be especially crucial in the case of a tight project schedule and limited time available for choosing SaaS vendor or application.

Fourth, our risk-related results shed some light on the cooperation between SaaS providers and adopters. Our findings illustrate that operational issues are of paramount importance for SaaS adopters and these should be secured by appropriate contracts and SLAs. In addition, our results highlight the importance of dependence on provider by revealing some importance of migration-related risk. This suggest the need of securing appropriate migration-supporting tools and clauses in contracts and SLAs.

Finally, our results illustrate that cost-related considerations might be underestimated or overlooked by practitioners. This might suggest that SaaS adopters and providers reveal a limited awareness of SaaS-related costs.

\section{Conclusion}

The current study investigated the role of risk and trust in the Software-as-a-Service (SaaS) adoption decision. In so doing, a multi-layered model explaining antecedents of the propensity to adopt SaaS has been proposed and validated using the Partial Least Squares (PLS) research approach. The employed research approach allowed us to conclude that trust plays a central role in the SaaS adoption decision both directly and indirectly influencing the decision to adopt SaaS and also being influenced by external factors, such as professional influence and external pressure. As such, the findings shed more light on the trust shaping mechanisms in the SaaS context illustrating the influence of external stakeholders. In addition, various types of risk have been analyzed and the significant role of operational risk has been found. The results achieved should be valuable for practitioners and researchers. Practitioners may draw from our findings while building trust and minimizing perception of risk in the SaaS context. They may also improve relationships between SaaS adopters and providers. Researchers, in turn, are encouraged to incorporate trust and risk as central concepts in their investigations into determinants of IT adoption in general and cloud computing in particular. 
The study limitations mainly result from the model's multidimensional construction. In this respect, trust is explained in only 25 percent, which suggests that it is especially advised to investigate additional antecedents of trust in future research. Risk factors, in turn, are identified to a much higher degree. Nevertheless, risk's $\mathrm{R}^{2}$ value of 0.64 highlights that other important types of risk influencing perceived generic risk of SaaS adoption exist and should be studied in further research. Another limitation concerns the small sample size, which limits the generalization of findings.

\section{Acknowledgements}

This publication has been financed in part by the subsidy granted to University of Gdansk and Cracow University of Economics, Poland.

\section{References}

[1] I. M. Sebastian, J. W. Ross, C. Beath, M. Mocker, K. G. Moloney, and N. O. Fonstad, "How Big Old Companies Navigate Digital Transformation", MIS Quarterly Executive (16:3), 2017.

[2] C. Matt, T. Hess, A. Benlian, , and F. Wiesboeck, "Options for Formulating a Digital Transformation Strategy", MIS Quarterly Executive (15:2), 2016.

[3] F. Abolhassan, "Pursuing Digital Transformation Driven by the Cloud", in The Drivers of Digital Transformation, 2016, pp. 1-11.

[4] J. W. Ross, I. M. Sebastian, C. M. Beath, and L. Jha, "Designing digital organizations-Summary of survey findings", MIT CISR, 2017.

[5] P. Gupta, A. Seetharaman, and J. R. Raj, "The usage and adoption of cloud computing by small and medium businesses", International Journal of Information Management, (33:5), 2013, pp. 861-874.

[6] S.-G. Lee, S. H. Chae, and K. M. Cho, "Drivers and inhibitors of SaaS adoption in Korea", International Journal of Information Management (33:3), 2013, pp. 429-440.

[7] A. Benlian, and T. Hess, "Opportunities and risks of software-as-a-service: Findings from a survey of IT executives", Decision Support Systems (52:1), 2011, pp. 232-246.

[8] T. Oliveira, M. Thomas, and M. Espadanal, "Assessing the determinants of cloud computing adoption: An analysis of the manufacturing and services sectors", Information and Management (51:5), 2014, pp. 497510.

[9] P. Mell, and T. M. Grance, "The NIST Definition of Cloud Computing", National Institute of Standards and Technology Special Publication, Gaithersburg (53), 2011.

[10] S. Schneider, and A. Sunyaev, "Determinant Factors of Cloud-Sourcing Decisions: Reflecting on the IT Outsourcing Literature in the Era of Cloud Computing",
Journal of Information Technology (31:1), 2016, pp. 131

[11] S. H. Kim, S. Y. Jang, and K. H. Yang, "Analysis of the Determinants of Software-as-a-Service Adoption in Small Businesses: Risks, Benefits, and Organizational and Environmental Factors", Journal of Small Business Management (55:2), 2017, pp. 303-325.

[12] S. K. Sharma, A. H. Al-Badi, S. M. Govindaluri, and M. H. Al-Kharusi, "Predicting motivators of cloud computing adoption: A developing country perspective", Computers in Human Behavior (62), 2016, pp. 61-69.

[13] E. M. Rogers, "Diffusion of Innovations", New York: Free Press, 1962.

[14] Gartner, "Gartner Says Global IT Spending to Grow $3.7 \%$ in 2020", Gartner Press Releases, 2019.

[15] B. Link, and A. Back, "Classifying systemic differences between Software as a Service- and On-PremiseEnterprise Resource Planning", Journal of Enterprise Information Management (28:6), 2015, pp. 808-837.

[16] W. L. Currie, "The organizing vision of application service provision: a process-oriented analysis", Information and Organization (14:4), 2004, pp. 237267.

[17] D. Gefen, I. Benbasat, and P. Pavlou, "A Research Agenda for Trust in Online Environments", Journal of Management Information Systems (24:4), 2008, pp. 275-286.

[18] D. H. Mcknight, V. Choudhury, and C. Kacmar, "The impact of initial consumer trust on intentions to transact with a web site: a trust building model", The Journal of Strategic Information Systems (11:3-4), 2002, pp. 297323.

[19] S. Simpson, "One year on: What exactly did the 2e2 collapse teach us?", The Register, 2014.

[20] R. Torres, “Center City's CloudMine, \$6M in debt, files for bankruptcy", Technically Media Inc., 2018.

[21] S. R. Marston, Z. Li, S. Bandyopadhyay, A. Ghalsasi, and J. Zhang, "Cloud Computing: The Business Perspective", SSRN Electronic Journal, 2009.

[22] O. Yigitbasioglu, "Modelling the Intention to Adopt Cloud Computing Services: A Transaction Cost Theory Perspective", Australasian Journal of Information Systems (18:3), 2014, pp. 193-2010.

[23] Gartner, "Magic Quadrant for Cloud Infrastructure as a Service, Worldwide", Gartner, 2019.

[24] W. Venters, and E. A. Whitley, "A Critical Review of Cloud Computing: Researching Desires and Realities", Journal of Information Technology (27:3), 2012, pp. 179-197.

[25] J.-W. Lian, D. C. Yen, and Y.-T. Wang, “An exploratory study to understand the critical factors affecting the decision to adopt cloud computing in Taiwan hospital", International Journal of Information Management (34:1), 2014, pp. 28-36.

[26] K. Hashizume, D. G. Rosado, E. Fernández-Medina, and E. B. Fernandez, "An analysis of security issues for cloud computing," Journal of Internet Services and Applications, 2013 (4:5), 2015. 
[27] D. Zissis, and D. Lekkas, “Addressing cloud computing security issues", Future Generation Computer Systems (28), 2012, pp. 583-592.

[28] S. Subashini, and V. Kavitha, "A survey on security issues in service delivery models of cloud computing", Journal of Network and Computer Applications (34:1), 2011, pp. 1-11.

[29] A. Rath, B. Spasic, N. Boucart, and P. Thiran, "Security Pattern for Cloud SaaS: From System and Data Security to Privacy Case Study in AWS and Azure", Computers (8:2), 2019, p. 34.

[30] B. Aubert, M. Patry, and S. Rivard, "Assessing the risk of IT outsourcing," Proceedings of the Thirty-First Hawaii International Conference on System Sciences, 1998.

[31] B. Bahli, and S. Rivard, "The Information Technology Outsourcing Risk: A Transaction Cost and Agency Theory-Based Perspective", Journal of Information Technology (18:3), 2003, pp. 211-222.

[32] D. Brook, "GDPR puts vendor contracts in the security spotlight", Computer Fraud and Security (2018:4), 2018, pp. 5-7.

[33] S. White, and V. Barber, "Software Asset Management Reaches a Tipping Point: SaaS Cost Management Eclipses License Compliance, Stephen White”, Gartner, 2017.

[34] T. Sautelle, and A. Biehl, "Top five 'must-dos' to contain SaaS costs", Snow Software, 2017.

[35] R. Zarnekow, and W. Brenner, "Distribution of cost over the application lifecycle - a multi-case study", Proceedings of the 13th European Conference on Information Systems, Information Systems in a Rapidly Changing Economy, 2005.

[36] European Commission, "Comparative study on cloud computing contracts", Publications Office of the EU, 2015.

[37] O. K. Ngwenyama, and N. Bryson, "Making the information systems outsourcing decision: A transaction cost approach to analyzing outsourcing decision problems", European Journal of Operational Research (115:2), 1999, pp. 351-367.

[38] A. Dutta, G. C. A. Peng, and A. Choudhary, "Risks in Enterprise Cloud Computing: The Perspective of it Experts", Journal of Computer Information Systems (53:4), 2013, pp. 39-48.

[39] D. Yimam, and E. B. Fernandez, "A survey of compliance issues in cloud computing", Journal of Internet Services and Applications (7:1), 2016, pp. 2-12.

[40] H. H. Teo, K. K. Wei, and I. Benbasat, "Predicting Intention to Adopt Interorganizational Linkages: An Institutional Perspective", MIS Quarterly (27:1), 2003, p. 19.

[41] E. B. Swanson, and N. C. Ramiller, "The Organizing Vision in Information Systems Innovation", Organization Science (8:5), 1997, pp. 458-474.

[42] S. G. Saya, L. G. Pee, and A. G. Kankanhalli, 2010. "The impact of institutional influences on perceived technological characteristics and real options in cloud computing adoption", ICIS 2010 Proceedings (24).
[43] P. J. DiMaggio, and W. W. Powell, "The Iron Cage Revisited: Institutional Isomorphism and Collective Rationality in Organizational Fields", American Sociological Review (48:2), 1983, pp. 147-160.

[44] J. F. Hair, G. T. M. Hult, C. M. Ringle, and M. Sarstedt, "A primer on partial least squares structural equation modeling (PLS-SEM)", Sage, 2017.

[45] R. P. Mcdonald, and M.-H. R. Ho, "Principles and practice in reporting structural equation analyses", Psychological Methods (7:1), 2002, pp. 64-82.

[46] S.-H. Hsu, W.-H. Chen, and M.-J. Hsieh, "Robustness testing of PLS, LISREL, EQS and ANN-based SEM for measuring customer satisfaction", Total Quality Management and Business Excellence (17:3), 2006, pp. 355-372.

[47] M. Sarstedt, C. M. Ringle, and J. F. Hair, "Partial Least Squares Structural Equation Modeling", in Handbook of Market Research, Springer, 2017.

[48] M. Kuciapski, "How the Type of Job Position Influences Technology Acceptance: A Study of Employees' Intention to Use Mobile Technologies for Knowledge Transfer", IEEE Access (7), 2019, pp. 177397-177413.

[49] J. Henseler, C. M. Ringle, and R. R. Sinkovics, "The use of partial least squares path modeling in international marketing", Advances in International Marketing New Challenges to International Marketing (20), 2009, pp. 277-319.

[50] J. F. Hair, J. J. Risher, M. M. Sarstedt, and C. Ringle, "When to use and how to report the results of PLSSEM", European Business Review (31:1), 2018, pp. 224.

[51] W. Chin, "The Partial Least Squares Approach to Structural Equation Modeling", Modern Methods for Business Research (8), 1998.

[52] P. Lustofin, P. Soja, and M. Kuciapski, "Investigating the Role of Business-IT Alignment in the Software-asa-Service Adoption Decision: A Preliminary Model", AMCIS 2020 Proceedings, 21, 2020.

[53] W.-W. Wu, "Mining significant factors affecting the adoption of SaaS using the rough set approach", Journal of Systems and Software (84:3), 2011, pp. 435-441.

[54] I. K. S. B. Amiruddin, „The Effect of Isomorphism Pressure and Accessibility of Financial Statements toward Stakeholder Trust with Financial Management Transparency as Mediation Variables (Study on Regional Government of the District/City in West Nusa Tenggara Province)", Global Journal of Management and Business Research: C Finance (18:7), 2018.

[55] S. Chou, and C. H., Chiang, "Understanding the formation of software-as-a-service (SaaS) satisfaction from the perspective of service quality", Decision Support Systems (56), 2013, pp. 148-155.

[56] S. Hair, J. F., Risher, J. J., Sarstedt, M. M., and C. Ringle, "When to use and how to report the results of PLS-SEM", European Business Review (31:1), 2018, pp. 2-24.

[57] Y. Wang, M. Wu and H. Wang, "Investigating the determinants and age and gender differences in the acceptance of mobile learning," British Journal of Educational Technology (40:1), 2009, pp. 92-11. 